\title{
Originals
}

\section{The Effects of Chlorpropamide and Insulin on Serum Lipids, Lipoproteins and Fractional Triglyceride Removal}

\author{
R. Paisey, R. S. Elkeles, J. Hambley, and P. Magill \\ Northwick Park Hospital and Clinical Research Centre, Watford Road, Harrow, Middlesex, England
}

\begin{abstract}
Summary. The effects of chlorpropamide on serum lipids, lipoproteins and fractional triglyceride removal have been studied over 12 months on 10 maturity onset diabetics not controlled on diet alone. Similar studies were carried out in 6 maturity onset diabetics who had failed to respond to sulphonylureas and 6 new insulin requiring diabetics. In the chlorpropamide treated patients there was an initial fall in serum and VLDL triglyceride but this effect was lost at 12 months. There was no change in fractional triglyceride removal. At 12 months there was a fall in LDL and a rise in HDL cholesterol. An initial improvement in glucose tolerance and insulin secretion was maintained at 12 months.

In the insulin treated group the initial fall in serum and VLDL triglyceride was maintained at 12 months and was accompanied by an increase in fractional triglyceride removal. There was also a fall in LDL and a rise in HDL cholesterol at 12 months.

The failure of chlorpropamide to maintain the reduction in serum and VLDL triglyceride could be of importance in the genesis of coronary heart disease in maturity onset diabetics. The fall in LDL and rise in HDL cholesterol found both with chlorpropamide and insulin might be beneficial.
\end{abstract}

Key words: Chlorpropamide, insulin, triglyceride, cholesterol, lipoproteins, VLDL, LDL, HDL, fractional triglyceride removal, diabetes.

The incidence of coronary heart disease (CHD) is greater in diabetics than in the normal population [1]. The reasons for this are not as yet clear. One factor could be the presence of hyperlipidaemia, which is frequent in untreated diabetics $[2,3]$. Though initial correction of hyperglyaemia in diabetes often corrects serum lipid concentrations, the longer term effects of treatment of diabetes on serum lipids are less clear. A high prevalence of hyperlipidaemia has been observed in treated diabetics $[4,5]$. We have therefore studied over 12 months the effects of chlorpropamide on serum lipids and lipoprotein composition in a group of maturity onset diabetics. We have also studied the effects of chlorpropamide treatment on the intravenous fat tolerance test, which is thought to be a measure of endogenous fractional triglyceride removal, as this could provide a clue to the mechanism of any observed changes in serum triglyceride concentration [6]. For comparison similar studies were carried out on the effects of insulin in a group of patients who had failed to respond to sulphonylurea therapy and in a group of new insulin requiring diabetics.

\section{Patients and Methods}

Fourteen new maturity onset diabetics were studied. Clinical details are given in Table $1 \mathrm{a}$. After 3 months on carbohydrate restriction alone their mean random blood glucose was $17.9 \mathrm{mmol} /$ 1 which was considered unsatisfactory. They were therefore given chlorpropamide $250 \mathrm{mg}$ daily and studied over the period of 1 year. They were asked to keep to the same diet as before and this was reassessed at least once during the study by the dietitian. During the year one patient died of a myocardial infarction. Two were changed to glibenclamide because of skin rashes and one developed cholestatic jaundice; these three patients were withdrawn from the study after 3 months.

The patients treated with insulin (Table $1 \mathrm{~b}$ ) included 6 who had continued hyperglycaemia and weight loss on diet and sulphonylurea, and 6 younger insulin requiring diabetics presenting with rapid weight loss, hyperglycaemia and ketonuria. None of these had severe acidosis (serum bicarbonate 15-20 mmol/l). All received twice daily Rapitard insulin except one who was given once daily Monotard insulin. As the results for both the groups treated with insulin were similar, they were analysed together. 
Table $1 \mathbf{a}$ and b. Clinical and biochemical data on chlorpropamide treated patients (a) and insulin treated patients (b). (Sulphonylurea failures GM-PO, new insulin requiring KR-PW). A - on diet alone in chlorpropamide group, or before insulin in insulin treated group, B after 1 month, C - after 3 months, D - after 12 months. \% DBW - \% Desirable Body Weight from Metropolitan Life Insurance Tables. *p $<0.02$ compared with $\mathrm{A}, * * \mathrm{p}<0.01$ compared with $\mathrm{A}$

\begin{tabular}{|c|c|c|c|c|c|c|c|c|c|c|c|c|c|c|c|c|c|c|c|}
\hline \multirow[t]{2}{*}{ Patient } & \multirow[t]{2}{*}{ Sex } & \multirow[t]{2}{*}{ Age } & \multirow[t]{2}{*}{$\% \mathrm{DBW}$} & \multicolumn{4}{|c|}{$\begin{array}{l}\text { Weight } \\
\mathrm{kg}\end{array}$} & \multicolumn{4}{|c|}{$\begin{array}{l}\text { Fasting blood } \\
\text { glucose } \\
\text { mmol/1 }\end{array}$} & \multicolumn{4}{|c|}{$\begin{array}{l}\text { Fasting serum } \\
\text { triglyceride } \\
\text { mmol/1 }\end{array}$} & \multicolumn{4}{|c|}{$\begin{array}{l}\text { Fasting serum } \\
\text { cholesterol } \\
\mathrm{mmol} / 1\end{array}$} \\
\hline & & & & A & B & C & $\mathrm{D}$ & A & B & $\mathrm{C}$ & $\mathrm{D}$ & A & B & C & $\mathrm{D}$ & A & B & $\mathrm{C}$ & $\mathrm{D}$ \\
\hline C. J. & $\mathbf{M}$ & 65 & 102 & 76.0 & 76.0 & 72.8 & 75.0 & 9.3 & 6.6 & 5.2 & 6.1 & 1.67 & 0.88 & 0.98 & 1.50 & 5.2 & 6.2 & 7.0 & 7.5 \\
\hline K. F. & $\mathbf{M}$ & 62 & 87 & 56.5 & 55.0 & 55.0 & 56.0 & 9.6 & 8.0 & 5.9 & 6.7 & 2.27 & 0.98 & 1.72 & 1.37 & 3.8 & 3.7 & 3.5 & 3.6 \\
\hline B. D. & $\mathrm{F}$ & 60 & 93 & 53.5 & 57.0 & 58.0 & - & 18.3 & 9.7 & 8.7 & - & 5.12 & 1.28 & 1.67 & - & 10.2 & 5.7 & 6.8 & - \\
\hline A. C. & $\mathrm{M}$ & 46 & 84 & 63.0 & 65.3 & 65.8 & 66.0 & 7.6 & 5.9 & 6.3 & 5.8 & 0.98 & 1.23 & 0.79 & 1.30 & 4.9 & 4.9 & 4.0 & 5.6 \\
\hline M. B. & $\mathrm{M}$ & 42 & 88 & 62.5 & 61.5 & 62.5 & 62.9 & 6.5 & 5.0 & 4.5 & 5.5 & 1.67 & 1.13 & 1.13 & 1.70 & 4.2 & 4.9 & 3.9 & 4.7 \\
\hline N. 1. & $\mathrm{~F}$ & 65 & 85 & 46.0 & 48.0 & 46.0 & 49.2 & 13.1 & 5.3 & 5.2 & 13.7 & 1.68 & 0.88 & 1.53 & 1.83 & 6.5 & 6.8 & 6.7 & 6.5 \\
\hline M. A. & $\mathbf{F}$ & 65 & 93 & 51.3 & 51.3 & 52.0 & 52.0 & 10.4 & 4.5 & 4.7 & 4.5 & 1.33 & 0.59 & 1.58 & 1.43 & 8.8 & 8.7 & 9.5 & 7.3 \\
\hline G. M. & $\mathbf{M}$ & 74 & 95 & 73.0 & 73.0 & 73.0 & - & 14.9 & 10.6 & 13.3 & - & 1.48 & 1.08 & 1.72 & - & 4.9 & 3.9 & 4.8 & - \\
\hline J. C. & $\mathrm{F}$ & 64 & 150 & 86.0 & 85.8 & 86.0 & 89.3 & 7.0 & 5.6 & 6.4 & 4.3 & 2.27 & 2.07 & 1.97 & 2.82 & 7.6 & 7.0 & 6.6 & 7.2 \\
\hline J. S. & $\mathbf{M}$ & 68 & 110 & 75.8 & 76.0 & 73.5 & - & 12.8 & 7.4 & 6.6 & - & 1.01 & 0.79 & 0.89 & - & 5.2 & 4.2 & 5.3 & - \\
\hline L. W. & $\mathbf{M}$ & 63 & 110 & 66.7 & 67.6 & 71.7 & 71.7 & 20.3 & 10.7 & 9.1 & 21.3 & 4.16 & 2.60 & 2.86 & 2.45 & 7.3 & 6.2 & 6.1 & 8.6 \\
\hline S. V. & $\mathrm{F}$ & 52 & 103 & 60.8 & 61.8 & 62.0 & 62.0 & 19.6 & 21.1 & 9.0 & 18.4 & 4.34 & 1.08 & 1.28 & 1.98 & 4.4 & 4.7 & 4.8 & 4.8 \\
\hline J. J. & $\mathrm{M}$ & 47 & 103 & 75.5 & 76.0 & 76.0 & - & 11.4 & 8.1 & 8.8 & - & 2.37 & 1.08 & 1.97 & - & 4.9 & 6.3 & 6.0 & - \\
\hline K. G. & $\mathbf{M}$ & 32 & 114 & 81.0 & 83.0 & 86.0 & 86.0 & 14.9 & 9.2 & 8.6 & 9.8 & 2.96 & 1.77 & 1.92 & 2.91 & 4.4 & 3.4 & 4.5 & $4 . \varepsilon$ \\
\hline Mean & & 57.5 & 101.2 & 66.3 & 67.0 & 67.1 & 67.0 & 12.6 & $8.4^{* *}$ & $7.3^{* *}$ & $9.6^{*}$ & 2.37 & $1.25^{* *}$ & $1.57^{* *}$ & * 1.92 & 5.9 & 5.5 & 5.7 & $6 . C$ \\
\hline SEM & & 3.2 & 4.5 & 3.2 & 3.1 & 3.2 & 3.4 & 1.2 & 1.1 & 1.5 & 2.0 & 0.34 & 0.14 & 0.14 & 0.19 & 0.5 & 0.4 & 0.4 & 0.5 \\
\hline
\end{tabular}

b

\begin{tabular}{|c|c|c|c|c|c|c|c|c|c|c|c|c|c|c|c|c|c|c|c|}
\hline G. M. & F & 57 & 118 & 68.0 & 70.0 & - & 70.3 & 18.2 & 6.5 & - & 17.3 & 1.80 & 1.48 & - & 0.97 & 7.6 & 6.2 & - & 6.2 \\
\hline R. C. & $\mathrm{F}$ & 59 & 93 & 49.0 & 50.0 & - & 54.8 & 15.6 & 16.2 & - & 6.7 & 2.86 & 2.45 & - & 0.68 & 6.9 & 5.3 & - & 7: \\
\hline I. M. & $\mathrm{F}$ & 52 & 80 & 49.0 & 52.0 & - & 61.0 & 10.6 & 14.8 & - & 12.4 & 1.23 & 0.79 & - & 1.05 & 5.6 & 5.8 & - & $5 .:$ \\
\hline A. $\mathrm{R}$. & $\mathbf{M}$ & 29 & 84 & 60.8 & 69.0 & - & 74.5 & 15.3 & 14.6 & - & 14.3 & 4.05 & 2.60 & - & 1.50 & 5.6 & 6.1 & - & 4: \\
\hline B. E. & $\mathrm{M}$ & 35 & 76 & 55.3 & 59.5 & - & 61.0 & 13.7 & 5.9 & - & 5.3 & 1.24 & 0.78 & - & 0.79 & 5.9 & 5.2 & - & 4.5 \\
\hline P.O. & $\mathrm{M}$ & 32 & 96 & 68.0 & 70.4 & - & 71.5 & 12.1 & 10.0 & - & 7.7 & 0.89 & 0.69 & - & 0.65 & 5.3 & 4.7 & - & $5 !$ \\
\hline K. R. & $\mathbf{M}$ & 19 & 89 & 63.0 & 69.0 & - & 75.2 & 15.0 & 7.0 & - & 6.9 & 2.07 & 0.69 & - & 0.58 & 4.7 & 4.7 & - & $3:$ \\
\hline E. M. & $\mathrm{F}$ & 30 & 78 & 48.0 & 54.0 & - & 58.0 & 13.6 & 3.7 & - & 5.6 & 1.85 & 0.69 & - & 0.45 & 4.8 & 3.6 & - & 4.1 \\
\hline J. B. & $F$ & 32 & 100 & 62.0 & 66.0 & - & 64.8 & 13.6 & 6.0 & - & 14.5 & 0.59 & 0.49 & - & 0.41 & 4.5 & 3.5 & - & 4.1 \\
\hline N. B. & $\mathbf{M}$ & 17 & 77 & 56.0 & 63.9 & - & 63.5 & 30.0 & 6.3 & - & 18.8 & 0.99 & 0.41 & - & 0.88 & 4.5 & 3.8 & - & $4 . i$ \\
\hline J. C. & $\mathbf{F}$ & 23 & 85 & 51.9 & 55.0 & - & 54.5 & 13.5 & 3.2 & - & 2.9 & 2.17 & 0.59 & - & 0.60 & 8.4 & 7.8 & - & 5.8 \\
\hline P.W. & $F$ & 32 & 73 & 44.7 & 52.0 & - & 49.0 & 15.0 & 5.1 & - & 6.0 & 0.59 & 0.18 & - & 0.17 & 4.8 & 3.3 & - & 3.. \\
\hline Mean & & 34.0 & 87.4 & 56.3 & $61.0^{* *}$ & - & $63.2^{* *}$ & 15.5 & $8.2 * *$ & - & $9.8^{* *}$ & 1.69 & $0.98^{* *}$ & - & $0.72^{* * *}$ & 5.7 & 5.5 & - & 5. \\
\hline SEM & & 4.0 & 3.7 & 2.3 & 2.3 & - & 2.4 & 1.4 & 1.3 & - & 1.5 & 0.41 & 0.22 & - & 0.10 & 0.7 & 0.5 & - & 0. \\
\hline
\end{tabular}

All patients were studied between 9 and 10 a. m. after an overnight fast. On the morning of the study, insulin or chlorpropamide was omitted. Blood samples were taken through an indwelling cannula. Blood taken for lipoprotein separation was allowed to clot and serum separated. Very low density lipoprotein (VLDL) was separated by preparative ultracentrifugation [7], which was started on the same day. Low density lipoprotein (LDL) and high density lipoprotein (HDL) were separated from the infranatant by heparin and manganese precipitation [8]. Total serum and fractionated lipoprotein triglyceride and cholesterol were measured by standard enzymatic methods using reagents purchased as assay kits from Boehringer Mannheim Corporation. The recovery in the lipoprotein analysis, i. e. the sum of cholesterol and triglyceride in the VLDL, LDL and HDL fractions, was within $100 \pm 13 \%$ of the total serum cholesterol and triglyceride. In those treated with chlorpropamide a 2 hour $50 \mathrm{~g}$ oral glucose tolerance test (OGTT) with measurements of serum insulin [9] was then carried out on each occasion. They were then given Intralipid (Vitrum) $(10 \%), 1$ $\mathrm{ml} / \mathrm{kg} \mathrm{i.} \mathrm{v.} \mathrm{for} \mathrm{the} \mathrm{intravenous} \mathrm{fat} \mathrm{tolerance} \mathrm{test} \mathrm{(IVFTT)} \mathrm{and} \mathrm{sam-}$ ples taken every 5 minutes for 35 minutes for spectrophotometric determination of the injected triglyceride [10]. The insulin treated patients were studied in an identical manner except that the OGTT was omitted. A $\mathrm{K}_{2}$ value was derived as a measure of fractional removal rate of the injected triglyceride. Preliminary studies indicated that a preceding 2 hour OGTT had no effect on the $K_{2}$ value of the IVFTT. This has also been shown for a preceding intravenous glucose tolerance test [11]

The chlorpropamide treated patients were studied after 3 months on diet alone, and at 1, 3 and 12 months after the start of chlorpropamide therapy. Those treated with insulin were studied before and at 1 and 12 months after starting insulin. 

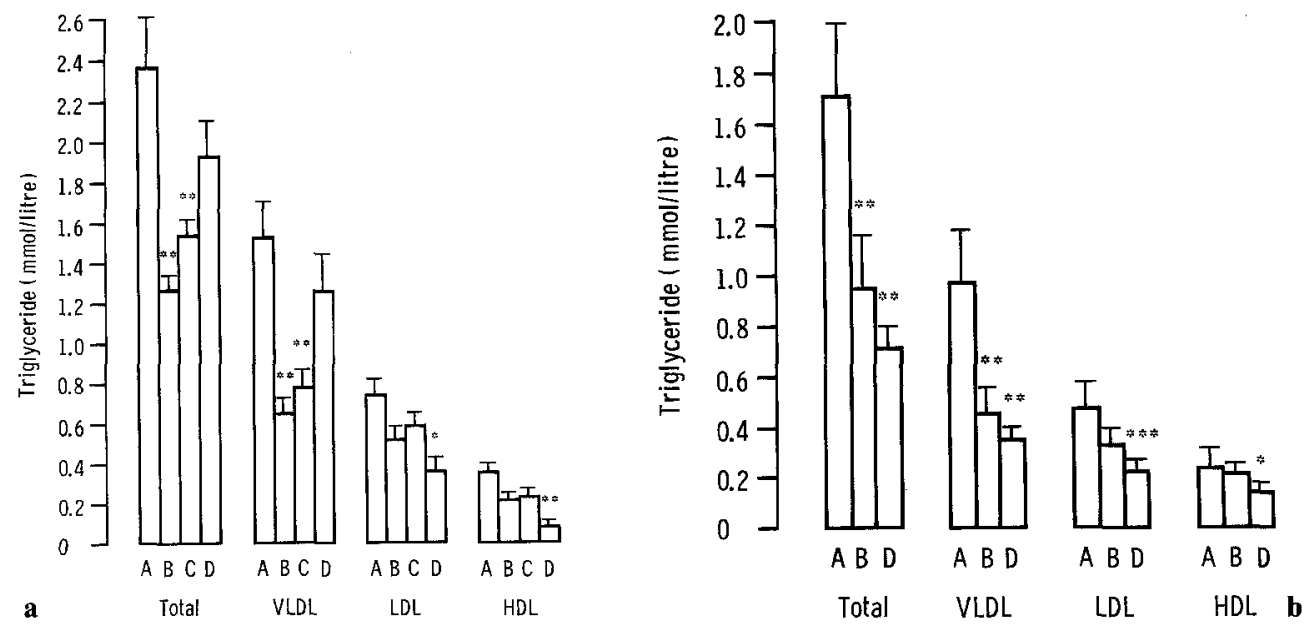

Fig. 1. a Total serum and lipoprotein triglyceride in chlorpropamide treated group (mean \pm SEM). A - on diet alone, B - 1 month, C - 3 months and D - 12 months after chlorpropamide. $\mathbf{b}$ Total serum and lipoprotein triglyceride in insulin treated group (mean \pm SEM). A untreated, B - 1 month, D - 12 months after insulin. $(* \mathrm{p}<0.05 * * \mathrm{p}<0.01 \quad * * * \mathrm{p}<0.001)$

\section{Results}

\section{Changes in Body Weight}

The chlorpropamide treated patients showed no significant change during treatment (Table $1 \mathrm{a}$ ). The insulin treated group showed a significant increase in weight after 1 month on insulin (Table $1 \mathrm{~b}$ ) with a small but not significant further increase after 12 months.

\section{Total Serum and Lipoprotein Triglyceride}

The chlorpropamide group showed a significant fall in total serum triglyceride at 1 and 3 months, but by 12 months serum triglyceride was approaching the pre-treatment level (Fig. 1 a). Similar changes occurred in VLDL triglyceride concentration. A significant fall in LDL and HDL triglyceride was observed at 12 months (Fig. 1 a).

In those treated with insulin there was a fall in total serum and VLDL triglyceride at 1 month which was maintained at 12 months. LDL and HDL triglyceride were all significantly reduced at 12 months (Fig. 1 b).

\section{Fractional Triglyceride Removal}

In those treated with chlorpropamide there was no change in $\mathrm{K}_{2}$ value during the study. In contrast, those treated with insulin showed a significant increase in $K_{2}$ value at 1 month and at 12 months (Table 2). The increase in fractional triglyceride removal correlated with the fall in serum triglyceride at 12 months $(\mathrm{r}=0.87, \mathrm{p} .<0.001)$.
Table 2. $K_{2}$ values (\% per minute mean \pm SEM) for fractional triglyceride removal rate in 12 insulin requiring diabetics and 10 maturity onset diabetics before and after treatment

\begin{tabular}{|c|c|c|c|}
\hline & Before treatment & 1 month & 12 months \\
\hline $\begin{array}{l}\text { Insulin gr } \\
\text { Chlorpro }\end{array}$ & 4.40 & $5.78 \pm 0.62$ & $7.00^{\mathrm{a}} \pm$ \\
\hline group & $2.34 \pm 0.31$ & $2.17 \pm 0.20$ & $2.21 \pm 0.18$ \\
\hline
\end{tabular}

a $K_{2}$ value significantly greater than before insulin $(p<0.001)$, and significantly greater than in chlorpropamide group $(\mathrm{p}<$ $0.001)$

\section{Total and Lipoprotein Cholesterol}

In the chlorpropamide group there was no change in total serum cholesterol (Fig. 2 a). There was a significant fall in LDL and rise in VLDL and HDL cholesterol at 12 months (Fig. 2 a). In the insulin treated group there was no change in total serum cholesterol (Fig. 2 b). VLDL cholesterol was significantly reduced at 1 and 12 months. LDL cholesterol was reduced, while HDL cholesterol was increased significantly at 12 months (Fig. 2 b).

\section{Glucose Tolerance and Insulin secretion}

The improvement in glucose tolerance in those treated with chlorpropamide found at 1 and 3 months was maintained at 12 months (Fig. 3 a) and was accompanied by a sustained improvement in insulin secretion (Fig. 3 b).

\section{Discussion}

We have shown that chlorpropamide lowered total serum triglyceride and VLDL triglyceride over 3 

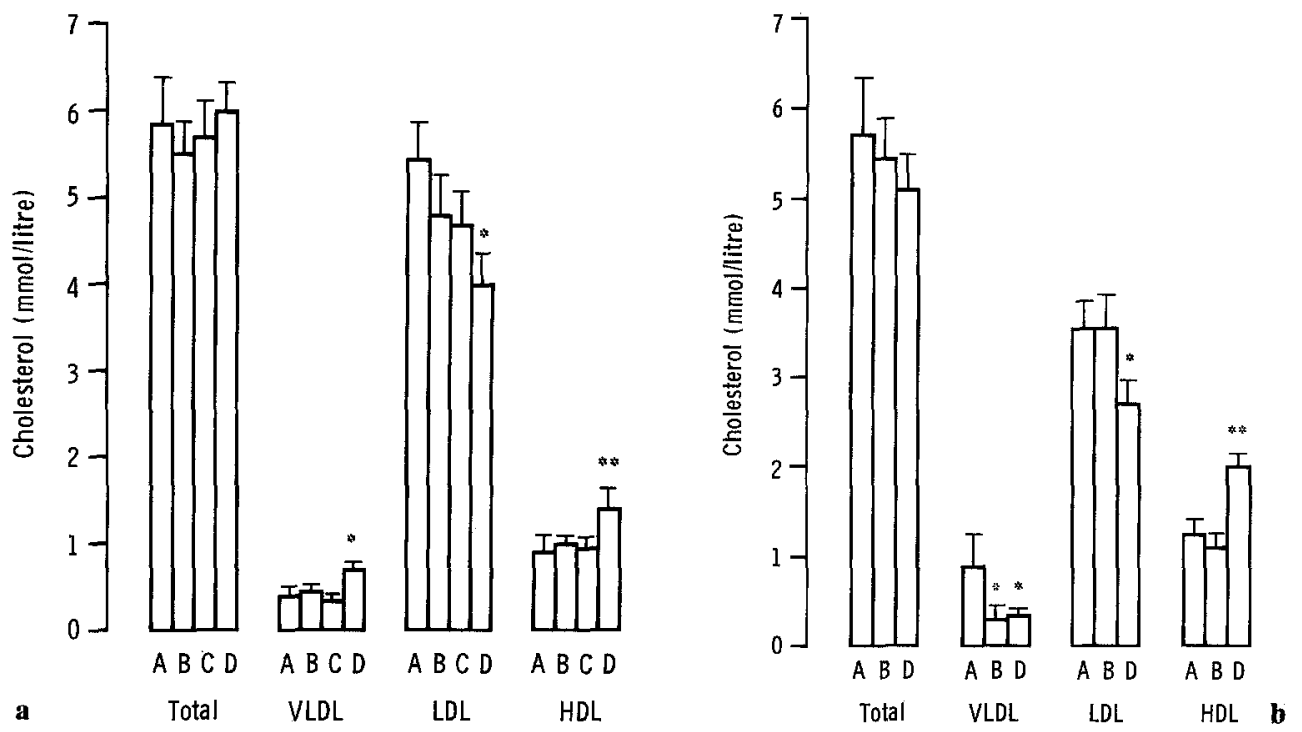

Fig. 2. a Total serum and lipoprotein cholesterol in chlorpropamide treated group (mean \pm SEM). b Total serum and lipoprotein cholesterol in insulin treated group (mean \pm SEM). Symbols as in Figure 1
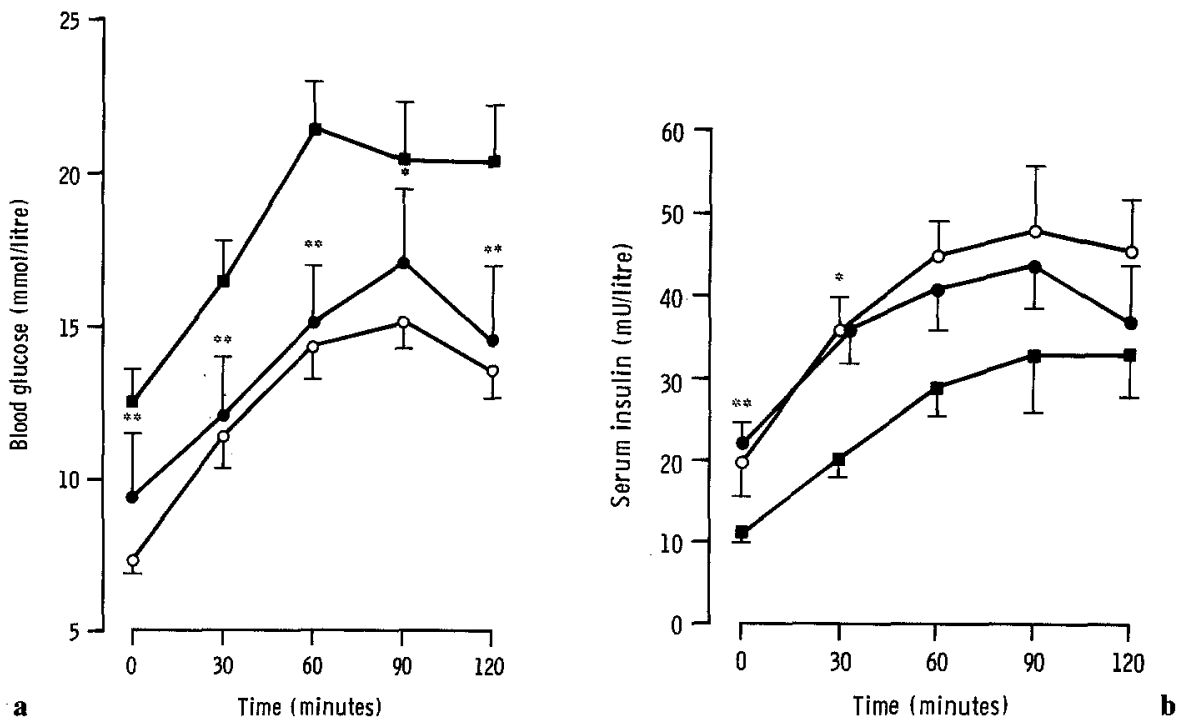

Fig. 3. a Blood glucose (mean \pm SEM) during OGTT in chlorpropamide treated group. b Serum insulin (mean \pm SEM) during OGTT in chlorpropamide treated group. $\square$ - on diet alone, $0-3$ months and - 12 months after chlorpropamide.

* $\mathrm{p}<0.05$ at 3 and 12 months compared with on diet alone

** $\mathrm{p}<0.01$ (N. B. For FBG at 12 months $\mathrm{p}<0.02$ ) compared with on diet alone

months but that this effect was lost at 12 months. This is in contrast to the hypoglycaemic effect of the drug in that the fasting and the $30,60,90$ and 120 minute blood glucose concentrations during the OGTT were all significantly lower at 12 months compared with before treatment (Fig. 3 a). There have been few previous studies on the effects of sulphonylureas on serum lipid concentrations. A reduction of serum triglyceride with chlorpropamide has been observed in maturity onset diabetics, but these studies were of shorter duration $[12,13]$. The failure of chlorpropamide to maintain a reduction in serum and VLDL triglyceride could be of relevance to the incidence of CHD in those treated with it. Hypertriglyceridaemia is probably a risk factor for CHD in the general population $[14,15]$ and diabetics with atherosclerotic vascular disease have been shown to have a higher serum triglyceride concentration and a greater frequency of pre-beta band staining than those without [16]. Treatment with insulin, on the other hand, resulted in a fall in total serum and VLDL triglyceride which was maintained at 1 year. 
The absence of any effect of chlorpropamide in enhancing fractional triglyceride removal suggests a different mode of action from insulin in its initial triglyceride lowering action. Correction of hyperglycaemia by insulin in insulin requiring diabetics has been shown to result in an increase in fractional triglyceride removal [17]. This was confirmed in our study. The insulin group had a higher $\mathrm{K}_{2}$ value before and after treatment than the chlorpropamide group which probably reflected their younger age [6]. The lower pretreatment value for $\mathrm{K}_{2}$ in the chlorpropamide group could also possibly account for the absence of a response after treatment. A study in which maturity onset diabetics are randomised into insulin and chlorpropamide treated groups would be necessary to exclude this possibility. The close correlation between increase in fractional triglyceride removal and decrease in serum triglyceride suggests that the main mechanism of the triglyceride lowering action of insulin is enhanced triglyceride removal. The absence of any effect of chlorpropamide on fractional triglyceride removal, in the presence of a clear stimulation of insulin secretion, suggests that the early effect of the drug in lowering VLDL triglyceride could have been due to a direct inhibition of hepatic triglyceride synthesis. This suggestion is supported by the finding that when VLDL triglyceride returned towards the pretreatment concentration at 12 months, the enhancement of insulin secretion was maintained (Fig. $3 \mathrm{~b}$ ). Thus the effect of chlorpropamide in lowering serum and VLDL triglyceride appeared to be transient and not related to its insulinotropic effect. There is no obvious explanation as to why the effect should be transient, but minor changes in diet insufficient to change body weight and not reported by the patients cannot be excluded.

The decrease in LDL cholesterol and increase in HDL cholesterol found both after chlorpropamide and insulin are of interest. Under some circumstances an inverse relationship has been found to exist between HDL and LDL cholesterol [18]. Furthermore a raised HDL cholesterol concentration has been thought to protect against CHD $[18,19,20]$ while a raised LDL cholesterol to predispose to it [21]. The actions of both chlorpropamide and of insulin in lowering LDL and raising HDL cholesterol might therefore be beneficial.

\section{References}

1. Pell, S., D'Alonzo, C. A.: Factors associated with long term survival in diabetics. J.A.M.A. 214, 1833-1840 (1970)

2. Albrink, M. J., Lavietes, P. H., Man, E. B.: Vascular disease and serum lipids in diabetes mellitus. Ann. Intern. Med. 58, 305- 323 (1963)
3. Elkeles, R. S., Wyllie, A. D. H., Lowy, C., Young, J. L. H., Fraser, T. R.: Serum insulin, glucose and lipid levels among mild diabetics in relation to the incidence of vascular complications. Lancet $1971 \mathrm{I}, 880-883$

4. Hayes, T. M.: Plasma lipoproteins in adult diabetes. Clin. Endocrinol. (Oxf.) 1, 247-251 (1972)

5. Perritt, A. D., Rowe, A. S., Shahmanesh, M., Allison, S. P., Hartog, M.: Blood lipids in treated diabetics. Diabetologia 10, 115-118 (1974)

6. Boberg, J., Carlson, L. A., Hallberg, D.: Application of a new intravenous fat tolerance test in the study of hypertriglyceridaemie in man. Atherosclerosis 9, 159-169 (1969)

7. Hatch, F. T., Lees, R. S.: Practical methods for plasma lipoprotein analysis. Adv. Lipid Res. 6, 1-68 (1968)

8. Burstein, M., Scholnick, H. R., Morfin, R.: Rapid method for the isolation of lipoprotein from human serum by precipitation with polyanions. J. Lipid Res. 11, 583-595 (1970)

9. Morgan, C. R., Lazarow, M. D.: Immunoassay of insulin: Two antibody system. Diabetes 12, 115-122 (1963)

10. Zollner, N., Hansen, W.: A photometric modification of the intravenous fat tolerance test. Atherosclerosis 15, 345-348 (1972)

11. Micheli, H., Rubba, P., Rossner, S.: The influence of a preceding intravenous glucose load on the intravenous fat tolerance test. Atherosclerosis 23, 363-365 (1976)

12. Carlson, L. A., Ostman, J.: Effect of chlorpropamide treatment on serum lipid levels in diabetes mellitus. Acta Med. Scand. 170, 561-564 (1961)

13. Morris, J. H., West, D. A., Bolinger, R. E.: Effect of oral sulphonylurea on plasma triglyceride in diabetics. Diabetes 13, 87-89 (1964)

14. Carlson, L. A., Bottiger, L. E. Ischaemic heart disease in relation to fasting values of plasma triglycerides and cholesterol. Lancet 1972 I, 865-868

15. Pelkonen, R., Nikkila, E. A., Koskinen, S Pentinnen, K., Sarna, S.: Association of serum lipids and obesity with cardiovascular mortality. Br. Med. J. 1977 I, 1185-1187

16. Santen, R. J., Willis, P.W., Fajans, S. S.: Atherosclerosis in diabetes mellitus. Arch. Intern. Med. 130, 833-843 (1972)

17. Lewis, B., Mancini, M., Mattock, M., Chait, A., Fraser, T. R.: Plasma triglyceride and fatty acid metabolism in diabetes mellitus. Eur. J. Clin. Invest. 2, 445-453 (1972)

18. Miller, G.J., Miller, N. E.: Plasma high density lipoprotein concentration and development of ischaemic heart disease. Lancet 1975 I, 16-19

19. Gordon, T., Castelli, W. P., Hjorstland, M. C., Kannel, W. B., Dawber, T. R.: High density lipoprotein as a protective factor against coronary heart disease. Am. J. Med. 62, 707-714 (1977)

20. Miller, N.E., Thille, D.S., Førde, O.H., Mjøs, O. D.: The Tromso Heart Study. High density lipoprotein and coronary heart disease. A prospective care-control study, Lancet 1977 I, 965-67

21. Kannel, W. B., Castelli, W. P., Gordon, T., McNamara, P. M.: Serum cholesterol, lipoproteins and the risk of coronary heart disease. Ann. Intern. Med. 74, 1-12 (1971)

Received: November 30, 1977,

and in revised form: March 7, 1978

Dr. R. S. Elkeles

Northwick Park Hospital

Clinical Research Centre

Watford Road

Harrow, Middlesex HA1 3UJ

England 